\title{
ПРОБЛЕМА ИНЕРТНОГО ЗНАНИЯ В ОСВОЕНИИ ГРАММАТИКИ ИНОСТРАННОГО ЯЗЫКА
}

\section{THE PROBLEM OF PASSIVE KNOWLEDGE IN LEARNING THE FOREIGN LANGUAGE GRAMMAR}

\section{Tarasova}

Summary: The article considers the problem of passive knowledge in learning the foreign language grammar. This problem is thought to be one of the most common among students in the process of applying the grammatical material in communication. The author analyzes the causes of this phenomenon and ways to overcome them in the classroom in a foreign language.

Keywords: grammar of a foreign language, the problem of passive knowledge, teaching English.
Тарасова Людмила Юрьевна

старший преподаватель, ФГБОУВО «Финансовый университет при Правительстве Российской Федерации»

(2. Москва)

tarasovkom@mail.ru

Аннотация: В статье рассматривается проблема инертного знания в освоении грамматики иностранного языка, являющаяся одной из наиболее распространенных трудностей, испытываемых учащимися в процессе применения изученного грамматического материала в коммуникации. Автором анализируются причины возникновения этого явления и пути их преодоления на занятиях по иностранному языку.

Ключевые слова: грамматика иностранного языка, проблема инертного знания, преподавание английского языка.
Д

овольно часто преподаватели сталкиваются с тем, что студенты не имеют сложностей в понимании изучаемого материала и его использовании в заданиях на занятии, но затрудняются использовать эти знания в коммуникативной ситуации того же занятия. В общении вне учебной аудитории они также часто испытывают сложности в использовании изученных языковых явлений. В первую очередь это касается грамматического материала.

Еще в 1929 году английский математик и философ Альфред Норт Уайтхед описал это явление, назвав его «проблема инертного знания». Знания грамматики, полученные в аудитории, остаются пассивными или инертными вне образовательной среды. Проблема инертного знания, несомненно, является источником фрустрации как для студентов, которые не способны применить изученный материал, так и у преподавателей, наблюдающих тщетность своих усилий [6].

Прежде чем обсудить способы решения этой проблемы, давайте обратимся к вопросу о том, нужно ли вообще изучать грамматику как отдельную составляющую языка.

Некоторые исследователи и преподаватели, в частности сторонники естественного подхода в обучении и радикальные приверженцы методики изучения языка путем решения поставленной задачи, утверждают, что исчерпывающие правила форм построения грамматических явлений не являются необходимой составляющей успешного овладения иностранным языком [1].
По их мнению, если студенты получают достаточно понятных примеров грамматических явлений в коммуникации, они самостоятельно идентифицируют для себя грамматические конструкции и осваивают их, как это происходит при освоении родного языка. Такое мнение основывается на предпосылке, что иностранный язык осваивается так же, как родной. Бесспорно, существуют студенты, способные усваивать грамматические конструкции непосредственно из речи. Однако сомнительной является теория, что все обучающиеся способны на это. Встречать в речи разнообразные грамматические явления языка не является достаточным для их усвоения и успешного самостоятельного использования в речи для многих студентов. Генеративная способность правил, позволяющая понимать и создавать утверждения на новом языке, является ценной для многих студентов, поскольку она дает чувство безопасности и уверенности. Сравнительный анализ грамматических структур изучаемого языка и грамматических структур родного и/или ранее изученных языков также способствует пониманию и более быстрому усвоению материала [3, 4].

Многочисленные исследования подтверждают, что без целенаправленного изучения грамматических явлений невозможно их самостоятельное правильное использование. В качестве примера приводятся случаи, когда обучающиеся находились в языковой среде на протяжении достаточно длительного времени, однако это не обеспечивало им необходимой подготовки в области грамматики, позволяющей использовать язык без ошибок. Таким образом, определенная доля грамматических правил является необходимой для формирования 
эффективных коммуникативных навыков студентов [5].

Однако преодоление проблемы инертности грамматических знаний не такая простая задача, как может показаться на первый взгляд. Использование языка грамматически и коммуникативно правильно - сложная задача. Ее скорее можно смягчить, анализируя методы преподавания и выявляя подходы, затрудняющие интеграцию грамматических навыков в речь, нежели окончательно решить. В частности, усугубить проблему может преподнесение грамматики как декларативного знания (знание правил о языке), в отличие от практического подхода, когда изучается, как использовать язык в эффективной коммуникации. Если воспринимать грамматику и коммуникативный процесс как совершенно разные явления, преподавание этих явлений тоже будет значительно отличаться, тем самым бремя их интеграции в речи будет перекладываться на студентов. Если они не смогут интегрировать их, они будут владеть сведениями о грамматике, но не смогут использовать эти знания в личной коммуникации.

Таким образом, эффективным способом смягчения проблемы инертного знания грамматики является коммуникативный подход в преподавании грамматических явлений. Рассмотрим несколько практических приемов реализации данного приема на примере преподавания грамматики английского языка.

Во-первых, необходимо помочь студентам заметить грамматическое явление в речи. Чтобы подсознательно привлечь внимание учащихся к изучаемому грамматическому явлению, можно выделить это явление в тексте для чтения (например, глаголы в Present Perfect). Преподаватель может выделять определенные суффиксы и префиксы в своей речи интонацией, если они являются изучаемой грамматической темой, например окончание -s у глаголов в Present Simple или отрицательные префиксы un-/in-/il-/im-/ir- и т.д. Повышение частотности употребления активируемой грамматической конструкции также способствует тому, чтобы учащиеся ее заметили и «прочувствовали» в контексте.

Во-вторых, важно приблизить условия использования грамматических структур к реальным, к ним, в частности, относятся отсутствие времени на подготовку и частичное владение информацией, которые, несомненно, психологически усложняют задачи. Вполне очевидно, что выполнение письменных грамматических упражнений, хоть и оправдано на начальном этапе ознакомления со структурой, но не приводит к использованию явления в коммуникации, следовательно, должно использоваться очень ограниченно.

В-третьих, необходимо учитывать и обращать внимание студентов на три разные грани, составляющие вкупе грамматику языка. Знание грамматических правил не является достаточным для грамотной речи, поскольку, опираясь только на правила, студенты иногда образуют конструкции, несвойственные для носителей языка («так не говорят»). Три составляющие грамматики - форма, значение и использование - взаимосвязаны, но представляют собой совершенно разные аспекты структуры. При этом форма отвечает за образование грамматической структуры, значение за смысл, который она несет, а использование - за случаи употребления. Как правило, одна из составляющих несет особую трудность для студентов, и каждой конструкции свойственна своя. Так, например, в сравнительной степени прилагательных вызывает затруднения форма (more boring или boringer), предлоги вызывают больше трудностей в области смысла, в области использования наибольшие трудности встречаются с Present Perfect и пассивными конструкциями. Учитывая трудности изучаемой конструкции, преподаватель может наиболее эффективно преподнести материал в рамках дефицита времени. При этом речь не идет об игнорировании других составляющих, кроме вызывающих трудности. Студенты должны знать о формировании, значении и использовании, однако область, вызывающая трудности, несомненно, требует повышенного внимания.

Как упоминалось выше, хотя знание грамматических форм, несомненно, важно, не менее важно знание о применимости конструкций в определенном контексте. Область использования часто недостаточно освещается, что приводит к усилению проблемы инертного знания. Когда две грамматические конструкции имеют очень близкое значение, то незначительное различие между ними и будет определять выбор между ними. К примеру, «It's a book» и «This is a book» грамматически правильные предложения. Но являются ли они взаимозаменяемыми? Нет. Указательные местоимения this, that, these и those используются для указания на близлежащие и удаленные предметы. Но они не используются для ответа на вопрос «What's this?». В этом случае используется личное местоимение - «lt's a book».

Для отработки использования прекрасно подходят ролевые игры, когда студентам в определенном контексте предлагаются две конструкции с похожим смыслом на выбор. В частности, для отработки использования Past Simple и Present Perfect, можно использовать ситуацию собеседования при приеме на работу, где претендент на должность описывает свою биографию, используя указанные времена:

Interviewer: Have you had any experience of working in a hotel?

Applicant: Yes, I have worked as a receptionist since last May. Before that I worked in a hotel bar for two years. 
При выборе необходимо также руководствоваться степенью формальности ситуации и разницей между письменным и устным стилем языка. Преподаватель должен также обращать внимание учащихся на то, что не всегда то, что свойственно носителям языка, может копироваться в речи учащихся.

Как упоминалось выше, многие студенты предпочитают детально разбирать грамматические правила, им нужны точные формулировки, что правильно, а что неверно. Однако, в языке многое зависит от контекста и нюансов смысла, поэтому сухое заучивание правил зачастую приводит к механическому теоретизированию и отрыву от реальной коммуникации. Необходимо ознакомить учащихся с понятием «оптимальная грамматика», подразумевающим, что различные грамматические структуры могут быть использованы для выражения различным оттенков смысла высказывания.

Помимо изучения правил и контекстуального выбора в каждом конкретном случае, необходимо мотивировать студентов к анализу выбора тех или иных языковых явлений носителями языка, как на примере письменных, так и устных высказываний $[2,7]$.

В частности, когда у говорящего есть возможность, он старается располагать новую информацию в конце предложения, как основной смысловой акцент. Прави- ла построения английского предложения не допускают свободного порядка слов, однако в ряде случаев выбор все-таки есть. К примеру, носитель языка не скажет "Mike is my name", когда будет представляться, поскольку в фокусе его высказывания находится его имя. Поэтому, "Му name is Mike" более адекватный вариант, несмотря на то, что оба предложения являются грамматически верными. Важно обращать внимание учащихся на такие особенности формулировки мыслей. Повторимся, однако, что в рамках строгого порядка слов английского предложения не всегда представляется возможным перенести новую информацию в конец предложения.

Многие студенты считают грамматику самой скучной составляющей изучения языка. Однако грамматика сама по себе не является скучной. Скучным можно сделать процесс освоения грамматики, если опираться на механическое заучивание правил и их использование в предложениях. Задача преподавателя - привить студентам отношение к грамматике, как к процессу и действию, а не как к набору знаний. Для этого необходимо предоставить студентам грамматическую практику в осмысленном контексте, интегрирующем форму и коммуникацию, сохраняя при этом фокус на изучаемом грамматическом явлении. Построение моста между грамматическими формами и их коммуникативном использовании в реальном общении является залогом успеха в преодолении проблемы инертного знания.

\section{ЛИТЕРАТУРА}

1. Б Благодетелева Н.К. Обучение студентов специальным умениям на занятиях иностранного языка в высшей школе // Теория и практика обучения иностранным языкам в неязыковом вузе: традиции, инновации, перспективы. Сборник научных трудов. Москва. 2014.

2. Мельничук М.В. Самоактуализация в процессе обучения иностранному языку в нелингвистическом вузе // Педагогический журнал. 2016. Т. 6. № 5А. C. $151-160$.

3. Holliday A. The struggle to teach English as an international language. Oxford Applied Linguistics, 2017. 280p.

4. Mohammad S., Hosseini H. Teach Language: A practical crash course. Scholars' Press, 2013. 164p.

5. Shams M.B. Effective way(s) of grammar teaching. Lambert Academic Publishing, 2014. 64p.

6. Thornbury S. How to teach grammar. Longman, 1999. 192p.

7. Walia D. English language teaching in engineering colleges. - Lambert Academic Publishing, 2012. - 124p.

(c) Тарасова Людмила Юрьевна (tarasovkom@mail.ru ). 